\title{
Acercamiento desde el existencialismo a la novela Sobre héroes y tumbas de Ernesto Sábato
}

\author{
Approach from Existentialism to the novel Sobre héroes y tumbas by Ernesto Sábato \\ Sindy Patricia Cardona Puello 1 iD \\ Fundación Universitaria Colombo Internacional Unicolombo- Colombia
}

\begin{abstract}
RESUMEN
La apertura de los escritores latinoamericanos hacia las corrientes estéticas de vanguardia durante la década del cuarenta (siglo XX) propició la acogida de ideas del existencialismo en el ámbito literario. Esto, sumado a las particularidades socioculturales de América Latina, produjo una inclinación de los escritores hacia la producción de obras que abordaban los temas caros a este movimiento tales como la historicidad, la angustia, el sentido de la existencia, la falta de armonía de las relaciones sociales y el declive del proyecto de la Modernidad. La obra narrativa de Ernesto Sábato fue influenciada por la literatura existencialista, de allí que este artículo de reflexión pretenda analizar la novela Sobre héroes y tumbas, publicada en 1961, para determinar los modos en que esta tendencia literaria se concreta en la obra.
\end{abstract}

Palabras clave: Existencialismo; literatura latinoamericana; modernidad; discurso literario.

\begin{abstract}
The opening of Latin American writers to the avant-garde aesthetic currents during the 1940s (twentieth century) allowed the introduction of existentialist ideas in the literary field. From this, there was an inclination towards the production of works that deal with issues of this movement such as historicity, existential angst, nonharmony of social relations and disappointment with the project of modernity. The narrative work of Ernesto Sábato was influenced by this movement, that is why this article tries to analyze the novel Sobre héroes y tumbas, published in 1961, to determine what aspects of the existentialist literature is present in her.
\end{abstract}

Key words: Existentialism; Latin American literatura; modernity; literary discourse.

Copyright: (C) 2020. Cardona, S. Este es un artículo de acceso abierto, distribuido bajo los términos de la licencia https://creativecommons.org/licenses/by-nc-

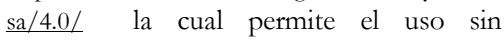
restricciones, distribución y reproducción en cualquier medio, siempre y cuando el original, el autor $y$ la fuente sean acreditados.

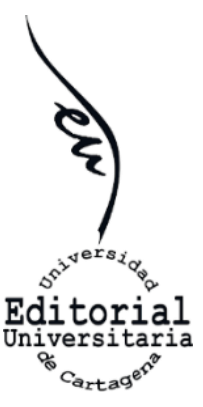

\footnotetext{
${ }^{1}$ Magíster en Estudios Latinoamericanos con Orientación en Cultura y Comunicación. Universidad Nacional de Cuyo (Mendoza, Argentina). Docente e investigadora de la Fundación Universitaria Colombo InternacionalUnicolombo.scardona@unicolombo.edu.co
} 


\section{INTRODUCCIÓN}

En América Latina se puede constatar la presencia del existencialismo en la literatura desde la primera mitad del siglo XX, dicha tendencia literaria, que cuestionaba el sentido de la vida y la naturaleza interior del ser humano, no se produjo de manera aleatoria, sino que surgió en respuesta a unas condiciones sociales, culturales y políticas propias del territorio latinoamericano. El existencialismo tendría, entonces, un gran valor para el campo literario de la región al igual que las narrativas posteriores pertenecientes al boom.

Con Juan Carlos Onetti y Ernesto Sábato se inicia un modo de novelar que enfatiza en el absurdo, la angustia y la soledad del ser humano ante la imposibilidad de armonizar con el entorno. Los escritores latinoamericanos que se relacionaron con esta tendencia durante la primera parte del siglo XX trabajaron los códigos estéticos con una postura crítica en torno a la sociedad y la condición humana, lo que evidencia un esfuerzo por comprender el mundo en su complejidad. De manera plenamente consciente en algunos casos, e indirecta en otros, dichos escritores pretendían generar un clima de introspección que condujera al lector al análisis de su realidad individual y colectiva.

Este artículo de reflexión, pretende precisamente, revisar una de las obras de Sábato bajo la perspectiva del existencialismo. Se trata de Sobre héroes y tumbas, una de las novelas más celebradas por la crítica latinoamericana por su compleja mirada sobre la condición humana. Si se atiende a los detalles formales, a las imágenes e ideas recurrentes en esta obra, es posible hallar una actitud de reflexión existencialista similar a la de los escritores europeos de la primera mitad del siglo XX que, agobiados por un clima social y político conflictivo, poblaron sus novelas de personajes problematizadores de lo social. Atender a dicho tema ofrece la posibilidad de revisar la historia de la literatura latinoamericana; de conocer y entender las diferentes poéticas que se han desarrollado en la región, y de observar de qué modo el lenguaje literario establece relaciones con la sociedad y con los sistemas de ideas que en ella tienen lugar.

\section{Irrupción del existencialismo en la literatura latinoamericana}

Los antecedentes de la trasformación de la novela en América Latina gracias a la narrativa vanguardista, se pueden encontrar a partir de la década del treinta del siglo XX con la aparición de varios escritores que empezaron a ocuparse de analizar desde una perspectiva intimista las condiciones sociales. Con las novelas Los siete locos (1929) y Los lanzallamas (1931), el escritor argentino Arlt “incorporó el «anti-héroe» a la narrativa urbana y ayudó a desmitificar la función del escritor omnisciente, demiurgo capaz de conjurar todos los destinos" (Aínsa, 1986, p. 42). La escritora chilena María Luisa Bombal, por su parte, publicó en 1935 La última niebla, en la que se evidencia el abandono de técnicas naturalistas por técnicas surrealistas de carácter onírico (Arango, 1989).

No obstante, es la década del cuarenta la época en que, según los críticos, se produjo un corte más claro, ya que durante estos años se identifica la preocupación por el cambio y la profesionalización del oficio de escritor como una tendencia presente en casi todo el continente. La literatura existencialista se introdujo, entonces, en la década del cuarenta en América Latina gracias a los narradores del Cono Sur, entre ellos el uruguayo Juan Carlos Onetti, cuya novela El pozo, publicada en 1939, 
representa los valores del existencialismo (Gertel,1970). Adicionalmente, a partir de 1945 se evidencia una matriz surrealista notablemente influenciada por el psicoanálisis y el existencialismo.

El existencialismo en la literatura alcanzó un punto álgido en la década del sesenta cuando ciertos autores como Ernesto Sábato alcanzaron su expresión más poderosa y cuando emergieron nuevos escritores que, animados por el estudio de autores como Miguel de Unamuno, Albert Camus, Sören Kierkegaard o Jean Paul Sartre, encontraron en esta tendencia una forma eficaz para expresar una visión acerca de la condición humana y de la situación del latinoamericano en particular.

Argentina fue uno de los países donde se produjo un gran interés por el existencialismo tanto desde lo filosófico como desde lo literario, de modo que varios de sus escritores abordaron desde la literatura el tema del sentido la existencia. Ernesto Sábato, nacido en la ciudad de Rojas (Provincia de Buenos Aires), es poseedor de una narrativa que explora hondamente, y con especial sensibilidad, los laberintos de la naturaleza humana.

El túnel, su primera novela, publicada en 1948, se enfoca en la psicología atormentada de los personajes, quienes ponen en cuestión el sentido de la existencia e intentan develar una respuesta a sus profundos interrogantes. En el discurso de esta primera obra ficcional se evidencian "las preocupaciones sabatianas sobre el aislamiento, la incomunicación, la angustia metafísica, los impulsos inconscientes, la desesperación, los celos, la esquizofrenia" según Varela (1994, p. 206). Similar a Mersault en La Náusea, Juan pablo Castel es presa de una angustia existencial, desconfía de "la opinión y de la justicia de los hombres" e ilustra la sensación de sin salida producto de la falta de comunión con el entorno:

\footnotetext{
Que el mundo es horrible, es una verdad que no necesita demostración. Bastaría un hecho para probarlo en todo caso: en un campo de concentración un expianista se quejó de hambre y entonces lo obligaron a comerse una rata, pero viva. (Sábato, El túnel, p. 8).
}

Dicha actitud existencial también aparece en Sobre Héroes y tumbas (publicada en 1961), considerada como una de las novelas más importantes en América Latina y con la cual Sábato alcanza una voz propia gracias a "una intensidad angustiosa que logra ensamblar lo subjetivo y lo objetivo para captar una totalidad que es tanto su circunstancia argentina como su afán de ver en ella la circunstancia del hombre universal" (Rama, 1982, pp. 155-156). Al igual que en su primera novela, aquí Sábato "ha tratado de analizar la condición de hombre que se interroga por el sentido de la vida" (Rosado,1999, p. 102).

Mediante una narración dialógica, esta novela aborda el universo emocional de los personajes y revisa, desde múltiples puntos de vista, los principales acontecimientos de la conformación de la nación argentina para mostrar las razones históricas de su fragmentación. Si bien el argumento central es el encuentro de Martín con Alejandra y el descubrimiento del mundo a partir de su compañía, subyace en la obra la preocupación por entender las razones de la crisis del hombre moderno. 


\section{De la profanación del amor y de otros metarrelatos}

Para entender el carácter existencial de Sobre héroes y tumbas se debe apelar al entramado de voces que portan discursos particulares acerca del sentido de la existencia. Son, en su mayoría, voces de seres desgarrados por sus propias historias familiares y por la conciencia de saberse habitantes de un mundo destrozado.

Martín Del Castillo, un muchacho de diecisiete años, entabla una relación problemática con Alejandra Vidal Olmos quien representa la última generación de una familia de antiguo prestigio político y social. Ambos jóvenes provienen de un entorno familiar desestructurado que no representa para ellos contención alguna; han estado abocados al abandono desde la infancia misma, cual seres arrojados que han tenido que aprender acerca del mundo y de las relaciones sociales de manera dolorosa.

El parricidio cometido por Alejandra refleja "el fracaso de su lucha por exorcizar los demonios interiores que la tienen encadenada a su pasión incestuosa" (Shaw, 1981, p. 56). Martín, por su parte, carga con el peso de saberse odiado por su progenitora desde el momento mismo de la concepción, y al sentirse rechazado por su "madrecloaca" se asume a sí mismo como un ser miserable y condenado al más absoluto desamparo. Así las cosas, estos personajes irán forjando desde temprana edad una visión trágica de la existencia, un impulso cuestionador del mundo y de las relaciones sociales. Con estos jóvenes se pone de manifiesto que las relaciones filiales en el mundo contemporáneo se encuentran en decadencia. La familia entra en crisis, y Martín y Alejandra se erigen como hijos de una modernidad decadente que al concentrarse en la transformación técnico-instrumental sacrificó la base axiológica del sentir humano.

\footnotetext{
Y entonces, como si hablara consigo mismo, [Martín] agregó que durante mucho tiempo había creído que no lo había amamantado por falta de leche, hasta que un día su madre le gritó que no lo había hecho para no deformarse y también le explicó que había hecho todo lo posible para abortar [...]. Así que podía imaginar con qué alegría lo recibió, después de luchar durante meses saltando a la cuerda como los boxeadores y dándose golpes en el vientre, razón por la cual (le explicaba su madre a gritos) él había salido medio tarado, ya que era un milagro que no hubiese ido a parar a las cloacas. (Sábato, Sobre héroes y tumbas, p. 22).
}

Los personajes de la novela están inmersos en un "mundo destrozado", noción acuñada por Gabriel Marcel (1953), con la cual describe al mundo contemporáneo que está abocado a la amenaza de su autodestrucción. La incesante voluntad de poder, el advenimiento de un estilo de vida mecanizado y desapasionado, la atomización que destruye los lazos fraternales en las sociedades civilizadas, y la imposibilidad del amor filial y de las causas fraternales, son las razones de la condición destructiva del mundo que revela Marcel, elementos que se hacen presente en el universo descrito en Sobre béroes y tumbas y que son objeto de reflexión por parte de los personajes.

La decadencia del amor filial y fraterno también agobia a los demás personajes que pueblan la historia. Fernando Vidal, padre de Alejandra, posee una frenética energía destructiva que durante la infancia lo llevó a intentar envenenar a su propio padre. También cabe destacar a Humberto D'Arcángelo, hijo de un cochero inmigrante italiano, quien representa la sensibilidad y el imaginario popular de la época; este 
cuenta con nostalgia cómo él y su padre fueron quedándose solos debido a la muerte, a la enfermedad y a la ingratitud que los alejó de la madre y de los siete hermanos; al final concluye con amargura que "así es la vida, pibe: yugá, tené hijo y a la final siempre te quedá solo como el viejo" (Sábato, Sobre héroes y tumbas, p. 104). $\mathrm{Al}$ igual que el amor filial, el amor romántico, como relato dador de sentido, se desdibuja. Con Alejandra, Martín descubre un tipo de mujer que no corresponde al rol prototípico de lo femenino, así como los tormentos, miedos y deseos que puede albergar el ser y que no por ser oscuros dejan de ser humanos. Es una especie de ser atormentado, incapaz de amar o de enternecer la existencia de alguien más: "Te he dicho, Martín, que soy una basura. No te olvidés que te lo he advertido" (Sábato, Sobre héroes y tumbas, p. 126). Esta joven mantiene, además, una profunda conflictividad con el erotismo, puesto que su atracción hacia al padre le obliga a negar las sensaciones corporales.

Por otro lado, la religión tampoco constituye para ninguno de los seres sabatianos un discurso estructurador de la vida. Fernando Vidal quien se autodenomina "nihilista" o "terrorista moral" profesa una profunda incredulidad ante la religión y cree que el "Príncipe de las Tinieblas" es quien gobierna el mundo mediante la "Secta Sagrada de los Ciegos". Vidal pone en crisis las creencias cuando se refiere a catástrofes, desigualdades e injusticias del mundo, puesto que le parece contradictoria la idea de un Dios omnipresente, omnisciente y bondadoso (Skrepetz, 2011, p. 19). Martín, por su parte, oscila entre la fe y la incredulidad; mientras que Alejandra expresa abiertamente su desprecio hacia lo divino; para ella ni Dios ni el infierno existen, sino como "un cuento de los curas para embaucar infelices".

\footnotetext{
Esa misma noche me arrodillé delante de mi cama y pedí a Dios que hiciera morir a mi tía Teresa [...]. Pero tía Teresa no murió [...]. Bueno, como te digo, al verla con tanta salud, todo el odio rebotó contra Dios [...]. Toda la pasión religiosa pareció de pronto invertirse, y con la misma fuerza. Tía Teresa había dicho que yo iba a ser una perdida y por lo tanto Dios también pensaba así, y no sólo lo pensaba, sino que seguramente lo quería. Empecé a planear mi venganza [...] rompí la cruz que había sobre mi cama, eché al inodoro las estampas y me limpié con el traje de comunión como si fuera papel higiénico, tirándolo después a la basura. (Sábato, Sobre Héroes y tumbas, pp. 65-66).
}

De otro lado, en esta novela son los jóvenes protagonistas los que llevan en su interior el germen de la angustia existencial y de la amargura, lo que acentúa su carácter crítico. Alejandra y Martín están lejos de representar el estereotipo de la juventud como fuerza social transformadora; además, personajes como Molinari, que en su juventud se permitieron luchar por un "mundo mejor" desde el anarquismo, son retratados como adultos decepcionados que después de sobrevivir a un proyecto político y social fallido se resignan a dejar pasar los días dando primacía a sus necesidades individuales.

Como le estaba diciendo, yo también en mis tiempos fui socialista y hasta anarquista [...] Soy de los que piensan que no es malo que la juventud tenga en su momento ideales tan puros. Ya hay tiempo de perder luego esas ilusiones. Luego la vida le muestra a uno que el hombre no está hecho para esas sociedades utópicas. (Sábato, Sobre héroes y tumbas, pp. 141-142). 
En pocas palabras, la igualdad y la fraternidad quedan puestas en entredicho en esta obra al igual que el amor, la religión, la utopía y el poder de trasformación de las juventudes, en tanto que su desdibujamiento se toma como la causa primera de la configuración de un mundo menos amable. Sobre héroes y Tumbas se configura, de este modo, como la recreación de un mundo destrozado.

Ahora bien, el hecho de proyectar dicho panorama, o de describir la situación del mundo desde un lugar de enunciación netamente crítico, es lo que configura el carácter existencialista de la obra. Al anterior el universo ficcional, los personajes hurgan por el sentido de vida, algunos desde el sentir y la observación espontáneos; otros, desde un registro discursivo más elaborado. También se siente el influjo existencialista en el hecho mismo de que el propio autor toma la novela como dispositivo para hacer su propio trabajo hermenéutico acerca del mundo y para mirar en perspectiva lo que ocurre con el ser humano.

\section{Interrogaciones al pasado histórico}

El existencialismo, como corriente filosófica, se preocupa por las circunstancias concretas que rodean al ser humano, por ello no puede dejar de abordarlo en su historicidad. Tanto los existencialistas ateos como los cristianos asumen la temporalidad como un rasgo importante del ser, quien se encuentra inmerso en un mundo concreto con unas situaciones epocales particulares: "el hombre no se entiende a sí mismo si no entiende su pasado, pero su pasado lo conecta con otros hombres, y a éstos se debe hacerles preguntas cruciales" (Abbagnano, 1969, p. 133). Entender el pasado se convierte, entonces, en un acto crucial para el sujeto que se preocupa por comprender su propia existencia y la de quienes coexisten con él.

Pues bien, en la novela de Sábato el pasado histórico es el eje que le da unidad a la narración. Los personajes indagan en la historia para poder encontrar respuestas a las condiciones del presente; toman distancia del mundo para colocarse por encima de él y evaluarlo. La voluntad de asumir el país en su realidad total es, de acuerdo con Balmer (1984), "unas de las notas más ambiciosas de Sobre héroes y tumbas" (p. 93).

Al visitar la vieja quinta, que perteneció a su otrora honorable familia, Alejandra revela a Martín parte de la historia de sus parientes remotos partícipes en la guerra civil entre federales y unitarios a principios del siglo XIX. Mientras reconstruyen su árbol genealógico, Alejandra y su bisabuelo Pancho Olmos dejan al descubierto la historia de luchas, alianzas y traiciones sobre la que se edificó la nación argentina. Rebuscando entre sus recuerdos, el bisabuelo (admirador de Juan Lavalle por "su buena fe, hombría de bien, caballerosidad y desinterés") cuenta que la familia se dividió a causa de Juan Manuel Rosas lo que dio origen a un resentimiento interno, análogo a lo sucedido en la sociedad argentina de la época. Si bien el abuelo y Alejandra valoran "aquellos hombres de verdad que se jugaban la vida por lo que creían" (Sábato, Sobre béroes y tumbas, p. 48), gracias a los distintos discursos que aparecen en la novela, lo que prevalece en la obra es un clima de conflictividad y de interrogación continua frente al papel que dicho pasado histórico jugó en la conformación de la Argentina actual. 
De manera paralela a las historias de vida de los personajes, Sábato introduce un relato del peregrinaje de la legión que se dirigió hacia Bolivia para proteger el cadáver de Juan Lavalle, líder de los unitarios durante la guerra civil. En una mezcla magistral de ficción y realidad histórica, el autor hace hablar a Juan Esteban Pedernera y a Alejandro Danel, quienes emprendieron la huida en 1841 para evitar que los federales se apoderaran del cuerpo del general. Las voces que describen este episodio memorable en la historia argentina, están colmadas de desencanto y dejan entrever la desesperanza al considerar que las disputas entre compatriotas no constituyen un buen legado para las generaciones futuras.

\begin{abstract}
Piensa Pedernera: veinticinco años de campañas, de combates, de victorias y derrotas. Pero en aquel tiempo sí sabíamos por lo que luchábamos. Luchábamos por la libertad del continente, por la Patria Grande. Pero ahora... Ha corrido tanta sangre por el suelo de América, hemos visto tantos atardeceres desesperados, hemos oído tantos alaridos de lucha entre hermanos... Ahí mismo viene Oribe, dispuesto a degollarnos, a lancearnos, a exterminarnos ¿no luchó conmigo en el Ejército de los Andes? El bravo, el duro general Oribe. ¿Dónde está la verdad? ¡Qué hermosos eran aquellos tiempos! ¡Qué arrogante iba Lavalle con su uniforme de mayor de granaderos, cuando entramos en Lima! Todo era más claro, entonces, todo era lindo como el uniforme que llevábamos... (Sábato, 2006: 85).
\end{abstract}

La peregrinación del cadáver de Lavalle simboliza al interior de la obra la melancolía por la muerte de los ideales de construcción una nación justa y solidaria. Alejandro Danel, el comandante que descarnó el cuerpo putrefacto del general, sentenció: "Y ahora, después de ochocientas leguas de tristeza, ahora marcho al lado de su cuerpo podrido, hacia la nada..." (Sábato, Sobre béroes y tumbas, p. 89). La nación argentina (como casi todas en América Latina) se construyó a sangre y fuego, a costa de cruentas guerras que propiciaron desde el inicio la fragmentación del territorio y de sus gentes. El sangriento enfrentamiento entre federales y unitarios fundó una nación escindida. En términos de González Molina (2009), la memoria es el medio por excelencia de la construcción narrativa en el universo de esta novela, pues a los sobrevivientes no les queda más que escudriñar en el pasado para descubrir y articular sus recuerdos y que les ayuden a comprender su difuso presente.

Sobre héroes y tumbas repasa, con una actitud existencialista, otros momentos cruciales de la historia argentina, tales como los enfrentamientos entre anarquistas y comunistas en la década del treinta del siglo XX y el bombardeo realizado sobre la Plaza de Mayo (Buenos Aires) en 1955 para provocar la caída de Juan Domingo Perón. Esto con el fin de observar de qué modo esos acontecimientos históricos dan cuenta de las características, temores y ambiciones que posee todo ser humano. Bruno, personaje de contemplación lúcida y melancólica que podría funcionar como alter ego de Sábato (Mamani, 2006), narra las profundas divisiones al interior del anarquismo, lo cual demuestra el carácter agonístico de la naturaleza humana y la voluntad de poder de los cuales no escapa ninguna ideología, ni siquiera los movimientos que se definen como libertarios.

Sin tomar partido por una posición en particular, la obra muestra el impacto que provocó el conflicto entre las distintas ideologías políticas en el sentir de la gente durante la década del cincuenta, es por ello que las voces que narran los acontecimientos de la persecución a Perón son las de los sujetos populares que experimentan directamente los efectos de los enfrentamientos. Al recrear la lucha 
anarquista y el conflicto peronista se pone nuevamente el acento en la crudeza de los enfrentamientos a causa de la polarización, y revela que los movimientos libertarios del presente contienen en su seno el mismo germen de violencia y rivalidad que los del pasado. Ambos momentos simbolizan la reactivación de los ideales decimonónicos de construir una patria mejor y al mismo tiempo representan la actualización de los fracasos del pasado.

De manera simultánea a las búsquedas internas de cada personaje, se teje una serie de relatos asociados al discurrir histórico representado no sólo desde la óptica de los próceres, sino también desde la sensibilidad de los sujetos populares que han presenciado los vaivenes de la historia y las transformaciones generacionales. En ese sentido, la novela ofrece la posibilidad de hallar una identidad del ser argentino teniendo en cuenta su historicidad, y el lector capta dicha esencia a partir de la isotopía que estructura su universo narrativo: el fracaso de los proyectos de construcción de nación.

Así que (pensaba Martín, mirando a Tito, que miraba a su padre) ¿qué es la Argentina? Preguntas a las que muchas veces le respondería Bruno diciéndole que la Argentina no sólo era Rosas y Lavalle, el gaucho y la pampa, sino también jy de qué trágica manera! el viejo D'Arcángelo con su galerita verde y su mirada abstracta, y su hijo Humberto J. D'Arcángelo, con su mezcla de escepticismo y ternura, resentimiento social e inagotable generosidad, sentimentalismo fácil e inteligencia analítica, crónica desesperanza y ansiosa y permanente espera de algo (2006: 192).

En suma, existe en la novela un péndulo que oscila entre la consciencia del individuo y su contexto existencial e histórico (Skrepetz, 2011: 24). Ahora bien, la dureza de este examen de la condición humana resultó particularmente inquietante para la época en que fue publicada esta novela. El inicio de la década de los sesenta en América Latina representó para varios sectores sociales el renacimiento de la utopía de construir una nueva sociedad latinoamericana. El impulso dado por la Revolución Cubana insufló en sectores campesinos, juveniles e intelectuales de la región los ánimos para emprender una nueva lucha armada que pusiera fin al intervencionismo extranjero y al monopolio de las oligarquías. Pero a pesar de este clima de relativo optimismo, Ernesto Sábato se permitió dudar de los proyectos a futuro e ir en contravía de las alegres expectativas, ya que poseía una visión compleja del ser humano y del modo como este ha respondido históricamente a los conflictos sociales.

\section{La nada en el corazón la urbe moderna}

Otras de las particularidades de la literatura existencialista en América Latina es la necesidad de entender las nuevas sensibilidades de la ciudad moderna, puesto que durante la primera mitad del siglo XX se produjo el crecimiento acelerado de las urbes de la mano con la modernización física e instrumental y la masificación de las comunicaciones. Dichos procesos transformaron los modos tradicionales de sociabilidad de los sujetos al interior de las naciones.

Mientras que el discurso de la modernidad impregnaba los programas políticos, sociales y económicos de los países latinoamericanos, los sujetos estaban experimentando un cambio radical en los modos de relacionarse con otros y con el espacio. Las costumbres al interior de las ciudades se modificaron conforme a la 
masificación dando paso a un tipo de relaciones e intercambios que se reducen a transacciones y prestación de servicios, debilitando la intersubjetividad entre sus habitantes.

$\mathrm{Al}$ no poder hallarse dentro de un espacio que antes era reconocido como propio, se produce el desencuentro entre las gentes de las ciudades y la imposibilidad de conservar las afinidades con el entorno. La literatura existencialista no es ajena a esta escisión, por tanto, en sus obras los personajes no mantendrán ya una relación afirmativa con el mundo, sino que "se enfrentarán a ese mundo, lo denunciarán despiadadamente" (Lamana, 1969, p. 15). El creciente interés en la ciudad moderna como un espacio de conflicto, fue denominada por Ángel Rama (1982) como "realismo crítico urbano", síntoma de la presencia de lo existencial en las obras latinoamericanas:

El descreimiento de los valores estatuidos se compensa por una afirmación de la experiencia personal, única que se presenta como segura y válida. El escritor habla de sí mismo, de su vivir en la sociedad, de lo que ve y sufre, de lo que actúa. Es por esta puerta por donde se establece la marca existencial que signa a la literatura crítica urbana de ese tiempo, más que por las lecturas de Sartre y Camus, que simplemente sirvieron de corroborantes de la orientación espontánea asumida (156).

La segunda parte de Sobre Héroes y tumbas titulada "Los rostros invisibles" es, precisamente, un recorrido por la sensibilidad de los sujetos populares que han experimentado los cambios a través del tiempo y que desde sus vivencias cotidianas también evalúan el mundo. Buenos Aires se erige como una urbe modernizada receptora de un gran número de inmigrantes que con sus costumbres e ideologías diversas hacen complejas las relaciones sociales y también la percepción de una identidad nacional. Si bien la gran afluencia de inmigrantes no es juzgada en la obra, es tomada como un tema esencial de análisis para entender las propiedades del ser argentino. El desamparo y la constante nostalgia de los inmigrantes por su tierra natal hacen mella en el territorio de llegada, ya que la melancolía (que se manifiesta en las prácticas de las personas exiliadas) se comparte con los nacionales y se transmite a las nuevas generaciones.

[Bruno] Se inclinó hacia la ciudad y volvió a contemplar la silueta de los rascacielos.

Seis millones de hombres, pensó. [...]

Seis millones de argentinos, españoles, italianos, vascos, alemanes, húngaros, rusos, polacos, yugoslavos, checos, sirios, libaneses, lituanos, griegos, ucranianos. Ob, Babilonia.

La ciudad gallega más grande el mundo. La ciudad italiana más grande del mundo. Etcétera. Más pizzerías que en Nápoles y Roma juntos. “Lo nacional”. ¡Dios mío! ¿Qué era lo nacional?

Ob, Babilonia. (2006: 157)

Con relación al cuestionamiento de la modernidad, unos de los personajes que más transmite al lector la zozobra ante los nuevos tiempos es Tito D’Arcángelo cuya familia es víctima, según explica, del progreso de la urbe. Al reemplazar los antiguos coches por un taxi para poder ponerse a tono con el progreso se sentenció, según él, la decadencia material y emocional de la familia. El cambio representa un gran 
traumatismo para este personaje y para todos aquellos seres que están hondamente ligados a la tradición.

\begin{abstract}
—Sabé —explicó con amargura_- un día le dijo que vendía la 40 y que con lo peso que se había juntado compraba a media un tasímetro. Te podé imaginar la bronca del viejo. Se enojó, lo insultó, rogó, pero todo fue inútil, porque Bachicha e duro como mármo. Te juro que si yo habría tenido en ese momento un ladrillo se lo tiro por la cabeza. Todo inútil. Se compró el tasi y se lo trajo aquí, pa mejor. El viejo estuvo a la cama como un me. Cuando se levantó ya no era el mismo de ante (Sábato, 2006:106).
\end{abstract}

Ahora bien, no sólo hay nostalgia en torno a la transformación física del espacio, sino también por la axiología que los personajes asociaban con la expresión de un mundo más amable. Alejandra y su bisabuelo valoran las virtudes de los hombres del pasado, pues Bruno, también lo hace: este personaje afirma que los Olmos (con excepción de Alejandra y Fernando) representan "el final de una antigua familia en medio del furioso caos de una ciudad cosmopolita y mercantilizada, dura e implacable" (2006: 413).

Pasando a otro punto, la visión trágica de la vida es llevada al extremo por Fernando Vidal voz principal del "Informe sobre ciegos" que constituye la tercera parte de la novela y que ha llamado mucho la atención de la crítica. Algunos analistas literarios se empeñan en considerar el "Informe sobre ciegos" como una metáfora de la disputa ideológica y literaria entre Sábato y Jorge Luis Borges (quien sufría de una ceguera congénita), sin embargo, esta interpretación fue rechazada por el propio Sábato durante una entrevista para Televisión Española (TVE, 1977) al calificarla como un "disparate total" que volvería minúscula la obra.

Dicho pasaje revela el libre ejercicio de la creación de toda obra existencialista, ya que de manera surrealista el personaje narra sus esfuerzos por descubrir el maléfico plan trazado, según él, por la logia de los ciegos para apoderarse del mundo. Aunque en esta parte las fronteras entre lo onírico y la realidad se tornan difusas, este capítulo representa para los lectores la radiografía de un ser escindido y en conflicto con el entorno. Con Fernando el pesimismo de los personajes existenciales es llevado a un nivel aún más radical. Para él todos los seres humanos representan una amenaza. El informe sobre ciegos es la manifestación del aspecto irracional del ser y de la existencia, y del poder del mal (Dellepiane, 1992).

La animadversión de Fernando hacia los ciegos, a quienes considera seres infernales, se extiende a cualquier ser humano, lo que lo convierte en un misántropo escéptico sobre el progreso espiritual o material de la humanidad. Este hombre desdeña las convenciones sociales, tiene una particular afición a las noticias policiales y declara abiertamente que el mal siempre prevalece. Uno de los momentos más representativos de este "héroe negro y repugnante" (como él mismo se hace llamar) es cuando en medio de su persecución a los ciegos termina internándose en las cloacas de la ciudad de Buenos Aires, hecho que se torna en una representación simbólica de la exploración de lo más oscuro del ser y de la ciudad. En esta novela se identifica, entonces, a la urbe moderna con una "ciudad cloaca" que alberga todos los vicios humanos; ello da cuenta de una visión escatológica de la ciudad que busca poner de manifiesto la soledad que sus habitantes llevan a cuestas y lo desagradable de las contradicciones sociales que subyacen en el mundo contemporáneo. 


\begin{abstract}
¡Abominables cloacas de Buenos Aires! ¡Mundo inferior y horrendo, patria de la inmundicia! Imaginaba arriba, en salones brillantes, a mujeres hermosas y delicadísimas, a gerentes de banco correctos y ponderados, a maestros de escuela diciendo que no se deben escribir malas palabras sobre las paredes; imaginaba guardapolvos blancos y almidonados, vestidos de noche con tules o gasas vaporosas, frases poéticas a la amada, discursos conmovedores sobre las virtudes patricias. Mientras por ahí abajo, en obsceno y pestilente tumulto, corrían mezclados las menstruaciones de aquellas amadas románticas, los excrementos de las vaporosas jóvenes vestidas de gasa, los preservativos usados por correctos gerentes, los destrozados fetos de miles de abortos, los restos de comidas de millones de casas y restaurantes, la inmensa, la innumerable Basura de Buenos Aires. (Sábato, 2006: 365).
\end{abstract}

\title{
Contrapunteo entre la esperanza y el nihilismo
}

Los personajes sabatianos se pueden interpretar, según Barreto (1992), desde la vía existencial, ya que representan toda una concepción de la especie humana enraizada en la angustia que se deriva de una situación de extrañamiento en el mundo. En medio del sombrío sentido de la existencia que dibuja la obra, se observa que los personajes son el producto de un mundo destrozado; Alejandra y su padre son el prototipo de ser atormentado incapaz de albergar esperanzas.

No obstante, en la última parte de la novela, titulada "Un dios desconocido", se produce un giro: aparece la esperanza como un pasaje hacía de redención. Al deambular embriagado por las calles, después de la trágica muerte de Alejandra, Martín pierde el conocimiento y despierta luego en la habitación de una mujer que, a pesar de su pobreza, le atiende con calidez. La candidez de dicha mujer y las ganas de honrar la bondad de Tito D'Arcángelo conducen a Martín a repensar su visión de la existencia; decide entonces emprender el viaje hacia el sur como un ritual de liberación de la soledad y de la anomía.

Aunque Martín contemplaba el suicidio como única forma de respuesta al quiebre del mundo, ejerció al final la libertad de elegir, llevando a cabo un acto existencial que le devolverá parte del sentido de la vida. Esta resolución no feliz, pero sí esperanzadora, representa para el lector un mensaje implícito de que pese a las pérdidas generadas por la lógica y los andares del mundo moderno aún se dispone de medios para sobreponerse a la angustia o a la amenaza del sin sentido. Después de explorar las razones de la angustia individual y colectiva, y de mostrar la imposibilidad de seguir creyendo en la religión y en el amor filial o romántico como relatos dadores de bienestar y de sentido, la obra estudiada contempla al final una solución que viene de parte de seres cotidianos, cuyo entendimiento del mundo no está dado por el racionalismo de una teoría, sino por la experimentación de la más pura contingencia.

Al final Sábato no sólo salva al personaje, sino también al lector, siendo consecuente con lo expresado en 1951: "Nuestro tiempo es el de la desesperación y de la angustia, pero paradojalmente sólo así puede abrirse la puerta de una nueva y auténtica esperanza [...] Mas ni la locura ni el suicidio pueden ser una solución genuina para el hombre" (1988: 82-83). 
El cierre de la novela es coherente con la filosofía existencialista manejada por el autor argentino: no fue Bruno (con su discurso teorético acerca de la vida, las emociones y los pensamientos) quien pudo ofrecer a Martín las razones para hallar el sentido de la existencia, sino las acciones esperanzadoras de los sujetos populares que conocen cómo y cuándo anteponer la solidaridad como valor supremo por encima de cualquier sistema de pensamiento. Y es que para Sábato la metafísica no reside únicamente en los vastos tratados filosóficos sino también en "las tribulaciones del modesto hombre de la calle" (Sábato, El escritor y sus fantasmas, p. 65), por ello no es extraño que en esta novela no aparezca el antihéroe intelectual a la manera de Antoine Roquentin, sino que sean los ciudadanos mismos los portadores de una visión especialmente nostálgica y cuestionadora de la modernidad.

Con el advenimiento de una posible salida, Sábato toma cierta distancia del existencialismo ateo de Sartre para quien "pareciera que no queda otra salida que la pura desesperación” (Sábato, Hombre y Engranajes, p. 86). La novela del argentino no abraza el existencialismo como nihilismo, sino como un examen profundo que pone de manifiesto las angustias, así como el instinto de vida o la capacidad de resiliencia del ser. El hecho de poner en cuestión la existencia no es en sí mismo una actitud pesimista; la reflexión existencial representaría una especie de "iluminación", de caer en cuenta: "Al reconocernos y al reconocer el mundo que nos ha sido dado, al enfrentarnos con él y aceptar que es ahí donde tenemos nuestro quehacer [...], es muy posible que encontremos ya razón suficiente para seguir viviendo" (Lamana, 1967: 14).

La diferencia entre la actitud existencialista de las novelas sartreanas y otras obras literarias ya había sido captada por Mario Vargas Llosa (1981), quien expresó su preferencia por la literatura de Albert Camus en lugar de la de Sartre, puesto que en ésta última el hombre parece compuesto sólo de ideas y el mundo parece un mero pretexto para formularlas. Según Vargas Llosa, en las obras del francés hay un desinterés por la poesía y una ausencia de misterio, ya que están pobladas de personajes que carecen de entusiasmos y que reflexionan en exceso.

Sobre Héroes y tumbas y la literatura existencialista latinoamericana entrañan una actitud que no solo se ocupa de racionalizar la existencia sino, que se ocupa, principalmente, de las sensibilidades de los sujetos que la experimentan. En la novelística contemporánea de América Latina se hace presente un discurso crítico al que el lector puede acceder solo si ha podido captar y comprender las emociones, sensibilidades y vivencias implicados en el universo narrado. En otros términos, en la literatura latinoamericana el posicionamiento discursivo y la reflexión filosófica no se imponen por encima del goce de la experiencia estética.

En América el existencialismo, por último, ganó nuevos matices al ir ligada a las preocupaciones particulares del ser latinoamericano (su identidad, su destino y su accidentada historia), lo cual explica que esta narrativa, luego de irrumpir en los años cuarenta, haya logrado prevalecer en el continente por varias décadas después. Incluso, hay estudiosos que se atreven a plantear que el existencialismo ha permanecido en América Latina hasta décadas recientes. El crítico uruguayo Jorge Majfud (2011), por ejemplo, sostiene que la "clausura existencial" (conciencia del sin sentido y de la no salida) no sólo se halla en Ernesto Sábato o en Juan Carlos 
Onetti, sino también en las novelas de varios escritores del continente que han publicado en la década de los ochenta. Majfud (2011) argumenta que, ante el fracaso de la utopía revolucionaria latinoamericana, varios escritores retornan a ciertos temas existencialistas como el escepticismo y la alienación social del individuo.

\section{CONCLUSIONES}

La novela de Ernesto Sábato es muestra de una estética común en varias obras latinoamericanas durante la década del sesenta y logra retomar en sus páginas el drama que experimenta el ser a causa de la ruptura con el espacio, de la inconformidad con la situación social y de la crisis de la modernidad. Se vale del diálogo, del monólogo y de la narración alternada de varios relatos para recrear las visiones de mundo de múltiples personajes.

La guerra civil entre federales y unitarios durante el siglo XIX es uno de los acontecimientos históricos relevantes a la hora de entender la ontología del ser argentino según muestra la obra sabatiana; sumado a esto, otros enfrentamientos históricos por el poder político tales como la lucha anarquista y el choque entre partidarios y detractores de Perón, completan el examen que hace el escritor argentino para hallar una explicación de las condiciones actuales. En ese gesto de revisión histórica se manifiesta una constante: el fracaso de los proyectos de nación; tanto los sectores políticos que ejercen el poder como los movimientos sociales que los disputan están atravesados por la vanidad y la voluntad de poder que impide que los proyectos colectivos conduzcan a una real libertad colectiva; entre tanto, los sujetos populares padecen los efectos negativos del caos y terminan sumidos en una profundo resentimiento y orfandad.

Esta novela presenta un acento metafísico que busca desnudar las pasiones y la esencia del ser que se ha forjado a partir de su historicidad. Siguiendo esta idea, la angustia y la actitud existencial en esta novela no es gratuita; su adopción no sólo responde a la intención de estar a la vanguardia con un estilo literario, sino que es producto, sobre todo, de un entorno social problemático. Sábato, según Lukavská (2007), configura en su novela un estado de crisis individual y social profunda; anuncia el peligro de la vida en la Nada y señala que el camino de salvación de la civilización occidental moderna pasa por el inconsciente o por las tinieblas del alma. En este sentido, mostrar a los hombres y mujeres con toda su carga de tragicidad, y configurar un universo narrativo con personajes emocionalmente desgarrados no constituye una apología al nihilismo, sino un acto de sinceridad que confronta al ser humano consigo mismo y lo conduce a apersonarse de su mundo.

El valor de la novela de Ernesto Sábato, está también en que aportó al campo literario latinoamericano un estilo particular de escritura que significó para muchos de los nuevos escritores un derrotero a seguir. Sus personajes representan la conciencia histórica del país, una historia llena de enfrentamientos, alianzas, traiciones y profundas transformaciones para alcanzar el progreso. Son personajes atormentados que al tratar de hallar las respuestas de su propia infelicidad se encuentra con el destino del país, allí hallan los rasgos del ser argentino y las razones históricas de su fragmentación. Es claro que Sábato desea rescatar al hombre fragmentado que ha perdido el pensamiento mágico o mítico, que antes daba sentido a su vida y que fue reemplazado por el "mitoide" de la tecnología y el progreso (Rosado, 1999). 


\section{Referencias bibliográficas}

Abbagnano, N. (1969). Introducción al existencialismo. México: Fondo de Cultura Económica.

Aínsa, F. (1986): Hacia un nuevo universalismo. El ejemplo de la narrativa del siglo XX. En Yurkievich, S. (Coord.), Identidad cultural de Iberoamérica en su literatura, (pp. 36-46). Madrid: Alhambra.

Arango, M. (1989). María Luisa Bombal. En: Origen y evolución de la Novela Hispanoamericana. (pp. 527-537). Bogotá: Tercer Mundo editores.

Balmer, P. (1984). El personaje de Alejandra en la novela "Sobre héroes y tumbas", de Ernesto Sábato. Revista Forma y Función, (2), 83-106.

Barreto, O. (1992). Incomunicación y soledad: evolución de un tema existencialista en la novela de Ernesto Sábato. Cauce, (14), 275-296.

Dellepiane, A. (1992). Entrevista con Ernesto Sábato en sus ochenta años. Revista Iberoamericana, LVIII(158), 33-44.

Gertel, Z. (1970). La novela hispanoamericana contemporánea. Buenos Aires: Nuevos esquemas.

Gilman, C. (2003). Entre la pluma y el fusil. Debates y dilemas del escritor revolucionario en América Latina. Buenos Aires: Siglo Veintiuno.

González Molina, O. (2009). Memoria y narración en la novela Sobre héroes y tumbas de Ernesto Sábato. Pensamiento y Cultura, 12(1), 161-172.

Lamana, M. (1967). Existencialismo y literatura. Buenos Aires: Centro editor de América Latina.

Lukavská, E. (2007). Mitos y símbolos en «Informe sobre ciegos» de Ernesto Sábato. Literatura Latinoamericana: historia, imaginación y fantasía. México: Plaza y Valdez.

Majfud, J. (2011). La clausura existencial y la clausura politica en la literatura latinoamericana. Disponible en http://majfud.org/2011/07/12/la-clausura-existencial-y-la-clausura-politica-en-laliteratura-latinoamericana/

Mamani, A. (2006). Requiem para un cóndor ciego: Juan Lavalle según la visión estetizada de la dupla Sábato-Falú". Probistoria X (10), 173-184.

Marcel, G. (1956). El misterio del ser. Buenos Aires: Editorial Sudamericana.

Rama, Á. (1982). La novela en América Latina. Panoramas 1920-1980. Bogotá: Procultura.

Rosado, J. (1999). Ernesto Sábato y la búsqueda de lo absoluto. Signos Literarios y Lingüísticos, I(1), 88-19.

Shaw, D. (1981). Una década de transición, 1940-50: Los rioplatenses. En Nueva Narrativa Hispanoamericana, (pp. 33-64.). Madrid: Ediciones Cátedra

Sábato, E. (1988). Ernesto Sábato: Hombres y engranajes. Heterodoxia. Madrid: Alianza Editorial.

Sábato, E. (2006). El escritory sus fantasmas. Buenos Aires: Seix Barral.

Sábato, E. (2006). El túnel. Buenos Aires: Seix Barral.

Sábato, E. (2006). Sobre Héroes y tumbas. Buenos Aires: Seix Barral.

Skrepetz, I. (2011). A concepção do mal em Ernesto Sabato. Anuário de Literatura, 16(1), 17-28.

Televisión Española. TVE. (1977). Entrevista con Ernesto Sábato. [video]. De https://www.youtube.com/watch?v=7Lx1 exJLPBQ

Varela Jácome, B. (1994). La estrategia novelística de Ernesto Sábato. En Hora actual de la novela bispánica, (pp.202-223). Chile: Universidad Católica de Valparaíso.

Vargas Llosa, M. (1981). Entre Sartre y Camus. Puerto Rico: Ediciones Huracán. 